\title{
A new strategy for mitigation of the allergenic activity of ovomucoid in hen eggs and beta-lactoglobulin in cow milk
}

\author{
Jun Kido ${ }^{1}$, Natsuko Nishi ${ }^{2}$, Sachiko Misumi ${ }^{2}$ and Tomoaki Matsumoto ${ }^{3 *}$ \\ ${ }^{1}$ Department of Pediatrics, Graduate School of Medical Sciences, Kumamoto University, Kumamoto City, Kumamoto, Japan \\ ${ }^{2}$ Department of Pediatrics, Kumamoto Regional Medical Center, Kumamoto City, Kumamoto, Japan \\ ${ }^{3}$ Pediatric Division, Aso Spa Hospital, Aso City, Kumamoto, Japan
}

\begin{abstract}
Recently, public interest in food allergies has been increasing because of increasing prevalence of these allergies among children. In Japan, hen egg and cow milk allergies account for nearly $50 \%$ of all cases of childhood food allergies. Patients with hen egg and cow milk allergies should avoid these foods and products that contain them until they have outgrown their allergies. However, regarding nutrition, quality of diet, and hyposensitization, it is significantly important for these patients to ingest hypoallergenic hen eggs, cow milk, and products that contain them. We previously demonstrated the mitigation of the allergenic activity of betalactoglobulin in cow milk and ovomucoid in hen egg by electrolysis. In this review, we discuss this new strategy for producing hypoallergenic hen eggs and cow milk.
\end{abstract}

\section{Introduction}

Food allergies continue to be an important human health problem. Recently, cases of food allergies have been increasing, with $5 \%-10 \%$ of infants and $1 \%-3 \%$ of school-age children in Japan affected by food allergies [1]. Hen eggs are most commonly responsible for food allergies, followed by cow milk. Patients with these food allergies develop adverse reactions, like urticaria, angioedema, wheezing, gastrointestinal symptoms, or anaphylactic shock, after ingestion of hen eggs, cow milk, or products that contain them.

Hen eggs are comprised of about $8 \%-11 \%$ shell, $56 \%-61 \%$ white, and $27 \%-32 \%$ yolk [2]. While the white is an aqueous protein solution ( $10 \%$ protein and $88 \%$ water), the yolk is composed of $50 \%$ water, $34 \%$ lipid, and $16 \%$ protein, giving it quite different properties. Egg white has been considered the most important source of allergens, with the ovomucoid (OMC; WHO/IUIS allergen name: Gal d 1), ovalbumin (Gal d 2), ovotransferrin (Gal d 3), and lysozyme C (Gal d 4) being the major allergens in it, but IgE-binding allergens have also been identified in the yolk. The characteristics of these four major egg white allergens are shown in Table 1. OMC and ovotransferrin are the most frequent allergens though it may depend on the reports.

Cow milk contains around 30-35 g of proteins per liter and includes more than 25 different proteins but only some of them are known to be allergenic. Table 2 provides the characteristics of cow milk allergens. Cow milk proteins consist of the coagulum containing the casein proteins and the lactoserum (whey proteins) representing $80 \%$ and $20 \%$ of the total milk proteins, respectively [3]. The casein fraction (Bos d 8) consists of four proteins that account for different percentages of the whole fraction: alphaS1-casein (Bos d 9), alphaS2casein (Bos d 10), beta-casein (Bos d 11), and kappa-casein (Bos d 12), with alphaS1-casein being the most important allergen of the casein fraction [4]. Allergens in the whey fraction are alpha-lactalbumin (Bos d 4), beta-lactoglobulin (BLG) (Bos d 5), immunoglobulins (Bos d 7), bovine serum albumin (BSA)(Bos d 6), and traces of lactoferrin (Bos $\mathrm{d}$ lactoferrin). Alpha-lactalbumin and beta-lactoglobulin are the most important allergens of the whey fraction, accounting for $5 \%$ and $10 \%$ of the total milk proteins, respectively $[3,5]$. There are only a few reports describing allergies to minor whey proteins such as immunoglobulin, BSA, or lactoferrin [6].

\section{Diagnosis of Hen Egg and Cow Milk Allergy and Effectiveness of The Skin Prick Test}

Conclusive diagnosis is crucial in patients with suspected food allergies. Double-blind, placebo-controlled food challenges are still the gold standard for diagnosing food allergies; however, these are time consuming, expensive, and troublesome for patients and involve risks of severe systemic reactions [7].

Table 1. Major egg white allergens.

\begin{tabular}{|c|c|c|c|c|c|c|}
\hline Protein & $\begin{array}{c}\text { Allergen } \\
\text { name }\end{array}$ & $\begin{array}{c}\text { Content in } \\
\text { dried egg } \\
\text { white (\%) }\end{array}$ & $\begin{array}{c}\text { Prevalence } \\
\text { in patients } \\
\mathbf{( \% )}\end{array}$ & $\begin{array}{c}\text { Size } \\
\text { (kDa) }\end{array}$ & pI & $\begin{array}{c}\text { Amino } \\
\text { Acids }\end{array}$ \\
\hline Ovomucoid & Gal d 1 & 11 & $34-97$ & 28.0 & 4.1 & 186 \\
\hline Ovalbumin & Gal d 2 & 54 & $9-100$ & 45.0 & 4.5 & 385 \\
\hline Ovotransferin & Gal d 3 & 13 & $22-94$ & 77.7 & 6.0 & 686 \\
\hline Lysozyme & Gal d 4 & 3.5 & $6-69$ & 14.3 & 10.7 & 129 \\
\hline
\end{tabular}

pI: isoelectric point

Correspondence to: Tomoaki Matsumoto, Pediatric Division, Aso Spa Hospital, 1153-1 Uchinomaki, Aso city, Kumamoto 869-2301, Japan, Tel.: +81-967-320881; Fax: +81-967-32-4462; E-mail: matsumoto@a.asospahp.jp

Key words: Hen egg allergy, cow milk allergy, ovomucoid, beta-lactoglobulin, electrolysis, $S-S$ protein allergen

Received: January 10, 2016; Accepted: January 22, 2016; Published: January 25, 2016 


\begin{tabular}{|c|c|c|c|c|c|c|c|}
\hline & Protein & Allergen name & $\begin{array}{c}\text { Concentration } \\
(\mathrm{g} / \mathrm{L})\end{array}$ & $\begin{array}{c}\text { Prevalence in patients } \\
(\%)\end{array}$ & Size (kDa) & pI & Amino Acids \\
\hline \multirow{5}{*}{ Whey } & Alpha-lactalbumin & Bos d 4 & $1-1.5$ & $0-67$ & 14.2 & 4.8 & 123 \\
\hline & Beta-lactoglobulin & Bos d 5 & $3-4$ & $13-62$ & 18.3 & 5.3 & 162 \\
\hline & Bovine serum albumin & Bos d 6 & $0.1-0.4$ & $0-76$ & 66.3 & $4.9-5.1$ & 582 \\
\hline & Immunogloblins & Bos d 7 & $0.6-1.0$ & $12-36$ & 160 & & \\
\hline & Lactoferrin & & 0.09 & $0-35$ & 80 & 8.7 & 703 \\
\hline \multirow{4}{*}{$\begin{array}{l}\text { Whole } \\
\text { casein }\end{array}$} & AlphaS1-casein & Bos d 9 & $12-15$ & $65-100$ & 23.6 & $4.9-5.0$ & 199 \\
\hline & AlphaS2-casein & Bos d 10 & $3-4$ & & 25.2 & $5.2-5.4$ & 207 \\
\hline & Beta-casein & Bos d 11 & $9-11$ & $35-44$ & 24 & $5.1-5.4$ & 209 \\
\hline & Kappa-casein & Bos d 12 & $3-4$ & $35-41$ & 19 & $5.4-5.6$ & 169 \\
\hline
\end{tabular}

pI: isoelectric point

Several diagnostic tests have been developed to predict outcomes of oral food challenges. Analysis of food-specific serum IgE levels $[8,9]$, the skin prick test (SPT) [10-12], and the atopy patch test [13] may be useful tools for diagnosing food allergies. However, the food challenge is still a crucial tool for definitively diagnosing food allergies, as analysis of food-specific serum IgE levels and the SPT do not currently render oral food challenges unnecessary in most cases [14]. The SPT is an important first-line procedure for evaluating food allergies, as it is quick and relatively inexpensive. Previously, we reported that measuring wheal sizes in the SPT and calculating the skin index (SI) could help diagnose many food allergies (e.g., to hen eggs, cow milk, wheat, and peanuts) [15]. Moreover, we performed the SPT in 126 children suspected to have CMA and 76 had positive oral provocation test results. We performed a logistic regression analysis to evaluate whether wheal diameters or SIs could predict CMA in these 126 patients. We found that wheal diameters and SIs could predict positive oral provocation test results. While the expected probabilities of having a positive oral provocation test result were $\geq 0.5$, the cut-off values for wheal diameters and SIs were $\geq 8 \mathrm{~mm}$ (79.5\% sensitivity and $76.7 \%$ specificity) and $\geq 1.0$ ( $77.3 \%$ sensitivity and $78.9 \%$ specificity), respectively.

Hill et al. [11] and Sporik et al. [16] showed that a 6-mm wheal diameter in children $<2$ years of age, or $8 \mathrm{~mm}$ in children $>2$ years of age, indicates $100 \%$ specificity of a clinical reaction. Saarinen et al. [17] reported $98 \%$ specificity and $92 \%$ positive predictive value (PPV) for $>8$-mm wheal diameter. Verstege et al. [12] reported 95\% PPV for a $12.5-\mathrm{mm}$ wheal diameter when pricked with fresh milk. Calvani et al. [18] reported 95\% PPV for a 15-mm wheal diameter in infants; this evidence supports results of our study, which shows that a $15-\mathrm{mm}$ wheal diameter had 90\% PPV.

\section{Treatment of Hen Egg and Cow Milk Allergy}

Patients with hen egg allergy (HEA) or cow milk allergy (CMA) should avoid these foods or products containing them until they outgrow HEA or CMA. However, it has been recently reported that oral immunotherapy by ingestion of these foods was able to achieve effective desensitization to these food allergies [19]. The egg white has a higher allergenic content than the yolk of the hen egg. Moreover, because raw hen eggs have greater allergenic content compared to cooked eggs, patients with HEA are likely to develop adverse reactions after ingestion of raw egg whites in the oral provocation test (OPT).
Many patients with HEA can ingest the cooked yolk, and some can even ingest the cooked egg white in small amounts. We should therefore assess their upper dose limit in the oral hen-egg provocation test. It is certainly important for daily nutrition and quality of diet of patients to be able to ingest a small amount of cooked egg.

Extensively hydrolyzed formulas (ehCMF) have been recommended as milk substitutes for infants with CMA. However, together with their unpleasant taste, these formulas present nutritional issues, such as growth reduction [20], decreased plasma protein concentrations and iron-binding capacity, and unbalanced plasma and urinary concentrations of some amino acids [20,21]. Furthermore, animals given hydrolysate formulas exhibited enhanced trypsin and chymotrypsin proteolytic activities in the intestine, higher cytochrome levels in the liver, and disrupted glucocorticoid metabolism [22]. Therefore, mitigation of the allergic action of cow milk, independent of the use of proteolytic enzymes, may be required. Partially hydrolyzed cow milk formulas (phCMFs) present therapeutic effects in infants with mild to moderate atopic dermatitis [23]. Although phCMFs are not considered substitute formulas for infants with CMA, we recently reported that 40 of $53(75 \%)$ children with CMA could ingest phCMF [24] without any adverse reactions. Additionally, most children presenting a $>6-\mathrm{mm}$ wheal diameter with phCMF could complete the OPT with phCMF [24]. Because phCMF includes larger molecular weight proteins compared to ehCMF [24], which do not pass through an ultra-filtration membrane, phCMF has higher allergenicity compared to ehCMF. Since phCMF is expected to retain more cowmilk antigens compared to ehCMF, early and long-term administration of phCMF may induce immunologic tolerance to cow milk antigens in children with CMA $[25,26]$. Extensive hydrolysis of cow milk generates considerable quantities of free amino acids, which causes bitterness. Since phCMF has been reported to taste better than ehCMF [27], phCMF may be more beneficial than ehCMF as a nutritional ingredient for drinks and food.

\section{Beta-lactoglobulin}

Beta-lactoglobulin (BLG), which is a prominent S-S protein allergen, is the main protein in whey, and has no counterpart in human breast milk. BLG is composed of nine beta-strands (beta-strand A-I) and one alpha helix; it is assumed that intermolecular hydrogen bonds between beta-strand-I main chains and intermolecular salt bridges between side chains of the loop (beta-strand-A and -B) play important 
roles in dimer formation [28]. The allergenic peptide $41 \mathrm{~V}-60 \mathrm{~K}$ contains beta-strand-B (41V-50P); the other allergenic peptide, 149L-162I, includes part of beta-strand-I (146H-151F). As B-cell epitopes are mostly conformational and dependent on the three-dimensional structure of antigens, heat denaturation of BLG has been studied to modulate its immunogenicity and allergenicity. Although decrease in IgE-binding ability of BLG has been demonstrated after heat treatment to some degree [29], heat-denatured BLG induces a more intensive local immunologic reaction in the gastrointestinal mucosa compared to native BLG [30].

The antigenicity of BLG has been reported to depend on its intramolecular S-S bonds, and can be reduced by thioredoxin through its catalytically active S-S groups, which causes lower allergenicity and enhanced digestibility [31].

\section{Ovomucoid}

The allergen protein content in hen eggs is mainly included in the egg white. Ovomucoid (OMC) has been identified as the most prominent allergen causing HEA and contains S-S bonds that may cause its allergic action [32,33]. OMC, composed of 186 amino acids, is a $28-\mathrm{kDa}$ protein with isoelectric point $\mathrm{pH} 4.1$. OMC consists of three tandem domains, each with nearly 60 amino acids, called Gal. d1.1, Gal.d1.2, and Gal.d1.3 [34]. Gal.d1.1 contains an $\alpha$-helix and three $\beta$-sheets. Each domain has three intramolecular S-S bonds, but no intermolecular S-S bond [35]. OMC is highly resistant to proteolytic enzymes and heat [36] and exhibits high allergic activity due to this structural feature.

\section{Electrolyzed Beta-lactoglobulin}

Although reduction of S-S bonds was expected during electrolysis on the cathode side, only short-term modulation of the redox potential and a low voltage difference was observed for whey proteins with a carbon electrode $[37,38]$. However, carbon electrodes are not approved for the modulation of food in Japan.

We reported that the allergic activity of BLG was markedly mitigated by a much higher voltage difference between platinum electrodes [39]. Briefly, we electrolyzed BLG as follows (Figure 1 in Kido et al. [40]). Heat-tight, 30-mm bore glass tubes were used in an $\mathrm{H}$-shaped electrolysis cell, connected with two tubes of $300 \mathrm{~mm}$ in length and one tube of $40 \mathrm{~mm}$ in length. The electrolysis was carried out using $1 \%$ BLG containing $1 \%$ sodium chloride for 30 minutes with a voltage difference of $90 \mathrm{~V}, 0.23 \mathrm{~A}\left(30 \mathrm{~mA} / \mathrm{cm}^{2}\right)$. The temperature of the electrolyte in both glass tubes was kept in the range of $12-18^{\circ} \mathrm{C}$ and the temperature next to the electrodes ranged from $40^{\circ} \mathrm{C}$ to $50^{\circ} \mathrm{C}$ during the electrolysis. Each BLG solution was then filtered through a 0.45 - $\mathrm{mm}$ filter unit.

In patients with CMA, the wheal size for BLG on the cathode side (cBLG) was markedly reduced in the SPT compared with untreated BLG (uBLG) or BLG on the anode side (aBLG), except in one patient with a serious systemic anaphylactic reaction to milk. The percent decrease in the wheal reaction with cBLG compared to uBLG (mean $71 \% \pm 28 \%$ ) was similar to that observed on comparison of the ehCMF with regular milk (mean $79 \% \pm 18 \%$ ), whereas the wheal size with aBLG was not affected significantly compared with uBLG [39]. Because the quantity of SH groups of BLG was decreased almost equally on both anode and cathode sides, the modulation of S-S bonds of BLG did not appear fundamentally associated with mitigation of its allergic action.

It has been postulated that the B-cell epitope of a protein with a rigid globular structure is localized on the molecular surface. Selo et al. [41] identified three peptide fragments as allergenic sites on the BLG molecule after tryptic digestion, i.e., residues $41 \mathrm{~V}-60 \mathrm{~K}, 102 \mathrm{Y}-124 \mathrm{R}$, and 149L-162I, all of which are exposed outside its rigid three-dimensional structure [42]. In our study, trypsin treatment of uBLG and aBLG clearly identified the two fragments, $41 \mathrm{~V}-60 \mathrm{~K}$ and 149L-162I, whereas no corresponding tryptic fragment was recovered for $\mathrm{CBLG}$ or apparent monomeric forms of BLG derived from the untreated or anode spots. The $\mathrm{uBLG}$ was detected as a single peak of a dimeric form of BLG in the gel filtration study [39], suggesting that native BLG is present in milk as a dimeric form. Allergic action was observed for uBLG and aBLG, and two antigenic fragments were distinctly separated in gels containing dimeric forms of uBLG and aBLG. Therefore, it seems likely that the dimeric form is highly involved in the allergic action of BLG, and the allergic action of the dimeric form of BLG is closely associated with two peptide fragments, $41 \mathrm{~V}-60 \mathrm{~K}$ and $149 \mathrm{~L}-162 \mathrm{I}$, on its surface [39]. This is of special interest, as the dimer and oligomers of cBLG showed similar mass-spectrometric patterns compared to monomeric BLG [39]. It is crucial to mitigate the sensitization potential of these modified proteins in nutritional formulas for infants at high risk of developing food sensitivity.

The allergenic peptide $41 \mathrm{~V}-60 \mathrm{~K}$ contains beta-strand-B (41V-50P), and the other allergenic peptide, 149L-162I, includes a part of beta strand-I (146H-151F). An SDS-PAGE study with complete reduction showed 35 - and 16-kDa bands for cBLG, whereas a single $18-\mathrm{kDa}$ band was seen for both uBLG and aBLG [39]. Alternatively, the dimeric structure of cBLG might be different from that of native BLG, causing conformational modulation with dislocation of allergenic peptides from the surface of BLG. Fifteen of 162 amino acids in the sequence of BLG are lysine residues. Lysine is an essential amino acid for the maintenance of the antigenic structure of BLG [43]. There were slightly fewer lysine residues on the cathode side than on the anode side. Various commercial BLG products are reported to be lactosylated to some degree [44], and reducing sugars like lactose favor the Maillard reaction via a Schiff base, between the aldehyde of the glucose moiety of lactose and an amino group of a protein, under conditions of heat and optimum $\mathrm{pH}$ [45]. Because a lactose-binding site of BLG was identified as being a lysine residue [44], the decrease in lysine residues may be due to the Maillard reaction during electrolysis.

Mitigation of the allergic action of cow milk, independent of hydrolyzation, may be beneficial, as there are some concerns about nutritional issues regarding hydrolysate formulas [20-22]. Additionally, the taste of whey, following electrolysis on the cathode side, was not altered. Therefore, our method may offer a new and more advantageous strategy of preparing hypoallergenic formulas for patients with CMA.

\section{Electrolyzed Ovomucoid}

There have been some reports of efforts to obtain hypoallergenic OMC. Cooke and Sampson [46] reported that the binding force of OMC to IgE antibodies decreased by approximately $28 \%$ when its intramolecular S-S bonds were cleaved by dithiothreitol (DDT), and this was particularly demonstrated in infants with hen egg allergy. Kato et al. [47] reported that the allergenic capacity of OMC was diminished when OMC was heated with wheat protein and was aggregated. This phenomenon was attributed to formation of intermolecular S-S bonds between the OMC and wheat protein, and the aggregation of OMC. When the solid component concentration of egg protein was $0.2 \%$ $0.3 \%$, $\mathrm{pH} 10-11.5$, and $\mathrm{OMC}$ was heated to $>80^{\circ} \mathrm{C}$, OMC was denatured and lost its high allergenic capacity [48]. Moreover, when OMC was 
treated at high pressure (100-400 MPa), the binding force between it and IgE antibodies decreased. Thus, tyrosine residues of OMC moved from the molecular entrail to the molecular surface.

We also showed that the allergenic capacity of OMC was attenuated after energization [40]. The electrolysis was carried out in the same way using $1 \%$ BLG containing $1 \%$ sodium chloride for 30 minutes with a voltage difference of $90 \mathrm{~V}, 0.23 \mathrm{~A}\left(30 \mathrm{~mA} / \mathrm{cm}^{2}\right)$. The wheal diameter for OMC on the polar opposites was reduced in the SPT compared with that of untreated OMC. In 21 patients with hen egg allergy, percentages of the wheal reaction with OMC on the cathode (cOMC) and anode $(\mathrm{aOMC})$ sides, compared to untreated $\mathrm{OMC}(\mathrm{uOMC})$, were $77.6 \% \pm$ $28.8 \%$ and $82.6 \% \pm 33.8 \%(P=0.004, P=0.030)$, respectively [40].

This phenomenon of mitigated allergenicity for OMC was evidently demonstrated in the $\mathrm{cOMC}$ and the quantity of $\mathrm{SH}$ groups in cOMC significantly increased. Some of nine S-S bonds in an OMC molecule were expected to be cleaved, which is in accordance with Cooke and Sampson's report [8] that the binding ability between OMC and IgE decreased when S-S bonds were cleaved upon addition of DDT. Our study suggests that an intramolecular S-S bond of OMC was cleaved by electric energy without use of a reducing agent such as DDT, and this cleavage contributed to decreased allergenic capacity [40]. We performed 2D electrophoresis with an irreducible solvent for uOMC, cOMC, and aOMC, with some extremely diverse spots being obtained (Figure 4 in Kido et al. [40]). We cut these relatively large spots out of the three respective gels, treated these proteins with trypsin, and then performed mass spectrometry for the peptide fragments of each gel. Moreover, we calculated the theoretical molecular weight of OMC and compared the theoretical value to the actual one obtained using mass spectrometry. In cOMC, a new formation of S-S bonds in $15 \mathrm{E}-24 \mathrm{~K}$, $57 \mathrm{E}-82 \mathrm{~K}$ and $122 \mathrm{R}-128 \mathrm{R}$, or $15 \mathrm{E}-24 \mathrm{~K}$, and $165 \mathrm{C}-185 \mathrm{~K}$ patterns were expected. In aOMC, a new formation of S-S bonds in $24 \mathrm{M}-14 \mathrm{~K}$, $130 \mathrm{E}-159 \mathrm{~K}$ and $57 \mathrm{E}-63 \mathrm{~K}, 165 \mathrm{C}-185 \mathrm{~K}$, and $18 \mathrm{D}-24 \mathrm{~K}$, or $90 \mathrm{~A}-121 \mathrm{~K}$ and $18 \mathrm{D}-24 \mathrm{~K}$ patterns were expected. Therefore, the S-S bond regions in $\mathrm{COMC}$ and $\mathrm{aOMC}$ were likely to have changed variously due to reactions other than reduction, and these changes were considered to contribute to the formation of hypoallergenic OMC.

\section{Conclusion}

In Japan, HEA and CMA account for nearly $50 \%$ of all cases of childhood food allergies. Although patients with HEA or CMA should avoid hen eggs, cow milk, or products that contain them, until they can outgrow HEA or CMA, it is significantly important for them to ingest hypoallergenic hen eggs, cow milk, or products containing them. An understanding of the mitigation of the allergenic activity of BLG and OMC by electrolysis may allow for its potential use in development of hypoallergenic hen egg or cow milk products or cooking methods.

\section{References}

1. Ebisawa M, Suqizaki C (2008) Prevalence of pediatric allergic diseases in the first 5 years of life. J Allergy Clin Immunol 121: S237

2. Poulsen LK, Hansen TK, Nørgaard A, Vestergaard H, Stahl Skov P, et al. (2001) Allergens from fish and egg. Allergy 56 Suppl 67: 39-42. [Crossref]

3. Wal JM (2004) Bovine milk allergenicity. Ann Allergy Asthma Immunol 93: S2-11. [Crossref]

4. Schulmeister U, Hochwallner H, Swoboda I, Focke-Tejkl M, Geller B, et al. (2009) Cloning, expression, and mapping of allergenic determinants of alphaS1-casein, a major cow's milk allergen. J Immunol 182: 7019-7029. [Crossref]

5. Docena GH, Fernandez R, Chirdo FG, Fossati CA (1996) Identification of casein as the major allergenic and antigenic protein of cow's milk. Allergy 51: 412-416. [Crossref]
6. Restani P, Ballabio C, Di Lorenzo C, Tripodi S, Fiocchi A (2009) Molecular aspects of milk allergens and their role in clinical events. Anal Bioanal Chem 395: 47-56. [Crossref]

7. Tanaka LG, El-Dahr JM, Lehrer SB (2001) Double-blind, placebo-controlled corn challenge resulting in anaphylaxis. J Allergy Clin Immunol 107: 744. [Crossref]

8. Sampson HA (2001) Utility of food-specific IgE concentrations in predicting symptomatic food allergy. J Allergy Clin Immunol 107: 891-896. [Crossref]

9. Celik-Bilgili S, Mehl A, Verstege A, Staden U, Nocon M, et al. (2005) The predictive value of specific immunoglobulin E levels in serum for the outcome of oral food challenges. Clin Exp Allergy 35: 268-273. [Crossref]

10. Eigenmann PA, Sampson HA (1998) Interpreting skin prick tests in the evaluation of food allergy in children. Pediatr Allergy Immunol 9: 186-191. [Crossref]

11. Hill DJ, Heine RG, Hosking CS (2004) The diagnostic value of skin prick testing in children with food allergy. Pediatr Allergy Immunol 15: 435-441. [Crossref]

12. Verstege A, Mehl A, Rolinck-Werninghaus C, Staden U, Nocon M, et al. (2005) The predictive value of the skin prick test weal size for the outcome of oral food challenges. Clin Exp Allergy 35: 1220-1226. [Crossref]

13. Niggemann B, Reibel S, Wahn U (2000) The atopy patch test (APT)-- a useful tool for the diagnosis of food allergy in children with atopic dermatitis. Allergy 55: 281-285. [Crossref]

14. Sampson HA (1999) Food allergy. Part 2: diagnosis and management. J Allergy Clin Immunol 103: 981-989. [Crossref]

15. Ueno H, Yoshioka K, Matsumoto T (2007) Usefulness of the skin index in predicting the outcome of oral challenges in children. J Investig Allergol Clin Immunol 17: 207210. [Crossref]

16. Sporik R, Hill DJ, Hosking CS (2000) Specificity of allergen skin testing in predicting positive open food challenges to milk, egg and peanut in children. Clin Exp Allergy 30: 1540-1546. [Crossref]

17. Saarinen KM, Suomalainen H, Savilahti E (2001) Diagnostic value of skin-prick and patch tests and serum eosinophil cationic protein and cow's milk-specific IgE in infants with cow's milk allergy. Clin Exp Allergy 31: 423-429. [Crossref]

18. Calvani M, Alessandri C, Frediani T, Lucarelli S, Miceli Sopo S, et al. (2007) Correlation between skin prick test using commercial extract of cow's milk protein and fresh milk and food challenges. Pediatr Allergy Immunol 18: 583-588. [Crossref]

19. Jones SM, Burks AW, Dupont C (2014) State of the art on food allergen immunotherapy: oral, sublingual, and epicutaneous. J Allergy Clin Immunol 133: 318-323. [Crossref]

20. Hernell O, Lönnerdal B (2003) Nutritional evaluation of protein hydrolysate formulas in healthy term infants: plasma amino acids, hematology, and trace elements. Am J Clin Nutr 78: 296-301. [Crossref]

21. Maggio L, Zuppa AA, Sawatzki G, Valsasina R, Schubert W, et al. (2005) Higher urinary excretion of essential amino acids in preterm infants fed protein hydrolysates. Acta Paediatr 94: 75-84. [Crossref]

22. Malikova NA, Krzhechkovskaia VV, Samenkova NF, Sazhinov GIu, Marokko IN (1993) Effect of milk proteins and their enzymatic hydrolyzates on non-specific resistance of some systems to food allergens. Vopr Pitan 26-30. [Crossref]

23. Jin YY, Cao RM, Chen J, Kaku Y, Wu J. et al. (2011) Partially hydrolyzed cow's milk formula has a therapeutic effect on the infants with mild to moderate atopic dermatitis: a randomized, double-blind study. Pediatr Allergy Immunol 22: 688-694.

24. Kido J, Nishi N, Sakaguchi M, Matsumoto T (2015) Most cases of cow's milk allergy are able to ingest a partially hydrolyzed formula. Ann Allergy Asthma Immunol 115: 330-331. [Crossref]

25. Fritsché R, Pahud JJ, Pecquet S, Pfeifer A (1997) Induction of systemic immunologic tolerance to beta-lactoglobulin by oral administration of a whey protein hydrolysate. $J$ Allergy Clin Immunol 100: 266-273. [Crossref]

26. Hays T, Wood RA (2005) A systematic review of the role of hydrolyzed infant formulas in allergy prevention. Arch Pediatr Adolesc Med 159: 810-816. [Crossref]

27. Pedrosa M, Pascual CY, Larco JI, Esteban MM (2006) Palatability of hydrolysates and other substitution formulas for cow's milk-allergic children: a comparative study of taste, smell, and texture evaluated by healthy volunteers. $J$ Investig Allergol Clin Immunol 16: 351-356. [Crossref]

28. Sakurai K, Goto Y (2002) Manipulating monomer-dimer equilibrium of bovine Beta -lactoglobulin by amino acid substitution. J Biol Chem 277: 25735-25740. [Crossref] 
29. Ehn BM, Ekstrand B, Bengtsson U, Ahlstedt S (2004) Modification of IgE binding during heat processing of the cow's milk allergen beta-lactoglobulin. J Agric Food Chem 52: 1398-1403. [Crossref]

30. Rytkönen J, Karttunen TJ, Karttunen R, Valkonen KH, Jenmalm MC. et al. (2002) Effect of heat denaturation on beta-lactoglobulin-induced gastrointestinal sensitization in rats: denatured betaLG induces a more intensive local immunologic response than native betaLG. Pediatr Allergy Immunol 13: 269-277. [Crossref]

31. del Val G, Yee BC, Lozano RM, Buchanan BB, Ermel RW, et al. (1999) Thioredoxin treatment increases digestibility and lowers allergenicity of milk. J Allergy Clin Immunol 103: 690-697. [Crossref]

32. Bernhisel-Broadbent J, Dintzis HM, Dintzis RZ, Sampson HA (1994) Allergenicity and antigenicity of chicken egg ovomucoid (Gal d III) compared with ovalbumin (Gal d I) in children with egg allergy and in mice. J Allergy Clin Immunol 93: 1047-1059. [Crossref]

33. Kovacs-Nolan J, Zhang JW, Hayakawa S, Mine Y (2000) Immunochemical and structural analysis of pepsin-digested egg white ovomucoid. J Agric Food Chem 48: 6261-6266. [Crossref]

34. Cooke SK, Sampson HA (1997) Allergenic properties of ovomucoid in man. J Immunol 159: 2026-2032. [Crossref]

35. Kato I, Schrode J, Kohr WJ, Laskowski M Jr (1987) Chicken ovomucoid: determination of its amino acid sequence, determination of the trypsin reactive site, and preparation of all three of its domains. Biochemistry 26: 193-201. [Crossref]

36. Urisu A, Ando H, Morita Y, Wada E, Yasaki T, et al. (1997) Allergenic activity of heated and ovomucoid-depleted egg white. J Allergy Clin Immunol 100: 171-176. [Crossref]

37. Bazinet L, Lamarche F, Boulet M, Amoit J (1997) Combined effect of pH and temperature during electroreduction of whey proteins. J Agric Food Chem 45: 101-107.

38. Bolduc MP, Bazinet L, Lessard J, Chapuzet JM, Vuillemard JC (2006) Electrochemical modification of the redox potential of pasteurized milk and its evolution during storage. J Agric Food Chem 54: 4651-4657. [Crossref]
39. Matsumoto T1 (2011) Mitigation of the allergenic activity of beta-lactoglobulin by electrolysis. Pediatr Allergy Immunol 22: 235-242. [Crossref]

40. Kido J, Matsumoto T (2015) Attenuated Allergenic Activity of Ovomucoid After Electrolysis. Allergy Asthma Immunol Res 7: 599-604. [Crossref]

41. Sélo I, Clément G, Bernard H, Chatel J, Créminon C, et al. (1999) Allergy to bovine beta-lactoglobulin: specificity of human IgE to tryptic peptides. Clin Exp Allergy 29: 1055-1063. [Crossref]

42. Takahashi T, Yamauchi K, Kaminogawa S (1990) Comparison between the antigenicity of native and unfolded beta-lactoglobulin. Agric Biol Chem 54: 691-697. [Crossref]

43. Song CY, Chen WL, Yang MC, Huang JP, Mao SJ (2005) Epitope mapping of a monoclonal antibody specific to bovine dry milk: involvement of residues 66-76 of strand D in thermal denatured beta-lactoglobulin. J Biol Chem 280: 3574-3582. [Crossref]

44. Leonil J, Molle D, Fauquant J, Maubois JL, Pearce RJ, et al. (1997) Characterization by ionization mass spectrometry of lactosyl beta-lactoglobulin conjugates formed during heat treatment of milk and whey and identification of one lactose-binding site. J Dairy Sci 80: 2270-2281. [Crossref]

45. Friedman M (1996) Food browning and its prevention: an overview. J Agric Food Chem 44: 631-653.

46. Cooke SK, Sampson HA (1997) Allergenic properties of ovomucoid in man. J Immunol 159: 2026-2032. [Crossref]

47. Kato Y, Oozawa E, Matsuda T (2001) Decrease in antigenic and allergenic potentials of ovomucoid by heating in the presence of wheat flour: dependence on wheat variety and intermolecular disulfide bridges. J Agric Food Chem 49: 3661-3665. [Crossref]

48. Hosono A, Ooi Y, Nakamura R (2004) Hypoallergenic egg white and a method of manufacturing hypoallergenic egg white. Japanese patent publication number 2004-261154(P2004-261154A).

Copyright: (C2016 Kido J. This is an open-access article distributed under the terms of the Creative Commons Attribution License, which permits unrestricted use, distribution, and reproduction in any medium, provided the original author and source are credited. 